\title{
Clear-Water Scour at Comparatively Large Cylindrical Piers
}

\author{
Rui M. Lança ${ }^{1}$; Cristina S. Fael ${ }^{2}$; Rodrigo J. Maia ${ }^{3}$; João P. Pêgo ${ }^{4}$; and António H. Cardoso ${ }^{5}$
}

\begin{abstract}
New long-duration clear-water scour data were collected at single cylindrical piers with the objective of investigating the effect of sediment coarseness, $D_{p} / D_{50}\left(D_{p}=\right.$ pier diameter; $D_{50}=$ median grain size $)$ on the equilibrium scour depth and improving the scour depth time evolution modeling by making use of the exponential function suggested in the literature. Experiments were carried out for the flow intensity close to the threshold condition of initiation of sediment motion, imposing wide changes of sediment coarseness and flow shallowness, $d / D_{p}(d=$ approach flow depth). The effect of sediment coarseness on the equilibrium scour depth was identified; existing predictors were modified to incorporate this effect for $U / U_{c} \approx 1.0 ; D_{p} / D_{50}>\approx 60$ and $d / D_{p} \geq 0.5$; the complete characterization of a known scour depth time evolution model was achieved for $U / U_{c} \approx 1.0,60<D_{p} / D_{50}<500$ and $0.5 \leq d / D_{p} \leq 5.0$. DOI: 10.1061/(ASCE)HY.19437900.0000788. (C) 2013 American Society of Civil Engineers.
\end{abstract}

CE Database subject headings: Bridges; Piers; Sediment; Scour.

Author keywords: Bridges; Cylindrical pier; Flow shallowness; Sediment coarseness; Local scour equilibrium depth; Local scour time evolution.

\section{Introduction}

It is widely recognized that local scour at bridge foundations is a common cause of bridges failure. In spite of the research efforts on this topic during the last five or six decades, the time evolution of scour depth and its ultimate equilibrium value remains a subject of concern for hydraulic engineers and researchers.

Research on local scouring has been made mostly through experimentation. The duration of most of the reported experiments was too short to guarantee equilibrium; also, most of them covered small sediment coarseness ratios, $D_{p} / D_{50}\left(D_{p}=\right.$ pier diameter; $D_{50}=$ median grain size). These time and coarseness limitations of experimental studies may be among the causes of reported discrepancies between field observations and predictions obtained through formulations derived from experimentation. That is reported, e.g., in National Cooperative Highway Research Program (NCHRP) (2011) or by Lee and Sturm (2009).

Time plays an important role in scour. It is well established that, under live-bed conditions, scour depth tends to equilibrium very quickly, while under clear-water conditions scour evolves much

\footnotetext{
${ }^{1}$ Assistant Professor, Departamento de Engenharia Civil, Instituto Superior de Engenharia, Universidade do Algarve, Campus da Penha, Faro 8005-139, Portugal (corresponding author).E-mail: rlanca@ualg.pt

${ }^{2}$ Assistant Professor, Departamento de Engenharia Civil e Arquitetura, Faculdade de Engenharia, Universidade da Beira Interior, Calçada Fonte do Lameiro, Covilhã 6200-358, Portugal. E-mail: cfael@ubi.pt

${ }^{3}$ Associate Professor, Departamento de Engenharia Civil, Faculdade de Engenharia, Universidade do Porto, Rua Dr. Roberto Frias, s/n, Porto 4200-465, Portugal. E-mail: rmaia@fe.up.pt

${ }^{4}$ Assistant Professor, Departamento de Engenharia Civil, Faculdade de Engenharia, Universidade do Porto, Rua Dr. Roberto Frias, s/n, Porto 4200-465, Portugal. E-mail: jppego@ fe.up.pt

${ }^{5}$ Full Professor, Departamento de Engenharia Civil, Instituto Superior Técnico, Universidade de Lisboa, Av. Rovisco Pais, 1, Lisbon 1049-001, Portugal. E-mail: antonio.cardoso@ist.utl.pt

Note. This manuscript was submitted on October 1, 2012; approved on June 4, 2013; published online on June 6, 2013. Discussion period open until April 1, 2014; separate discussions must be submitted for individual papers. This paper is part of the Journal of Hydraulic Engineering, Vol. 139, No. 11, November 1, 2013. (C) ASCE, ISSN 0733-9429/2013/11-1117-1125/\$25.00.
}

slower. Ettema (1980) identified three phases of the scouring process: the initial phase, the principal phase, and the equilibrium phase, assumed to occur when the scour depth practically does not increase anymore. In clear-water scour, the principal phase lasts for a long time and the equilibrium scour depth is approached asymptotically.

Many researchers attempted to develop equations to predict local scour time evolution. Franzetti et al. (1982) proposed an exponential function that involves the equilibrium scour depth, $d_{s e}$, and two coefficients, $a_{1}$ and $a_{2}$. Melville and Chiew (1999) introduced a time factor in their scour predictor that includes the time needed to attain equilibrium, i.e., time to equilibrium. This time factor was recently modified by Melville and Sheppard as reported in NCHRP (2011). Oliveto and Hager $(2002,2005)$ developed a predictor that was not aimed to be valid up to the equilibrium phase. More recently, Kothyari et al. (2007) kept the structure of Oliveto and Hager's model but included a criterion for an ultimate scour depth which occurs at time to equilibrium.

The equilibrium concept is rather subjective and different authors present different approaches to cope with it. Some argue that equilibrium is reached in a finite time (Melville and Chiew 1999; Kothyari et al. 2007). Others state that equilibrium scour cannot be achieved in a finite time (Franzetti et al. 1982) or implicitly discard that scour depth values are upper bounded.

In this work, it is assumed that equilibrium scour is achieved in infinite time. The question of how long should experiments last to sufficiently approach equilibrium emerges. According to Lança et al. (2010), the extrapolation to infinite time of at least seven-day-long scour depth records, adjusted by a six-parameter polynomial function, renders robust values of the equilibrium scour-depth at single cylindrical piers characterized by $D_{p}$ in the range $63 \mathrm{~mm}<D_{p}<80 \mathrm{~mm}, d / D_{p} \approx 2.0$ and $49<D_{p} / D_{50}<93$. Simarro et al. (2011) performed a comparative study of different contributions and concluded that the exponential function of Franzetti et al. (1982) describes scour-depth time evolution with a noticeable precision, with the advantage of using only two coefficients $\left(a_{1}\right.$ and $\left.a_{2}\right)$ and the equilibrium scour depth, $d_{s e}$. In this study, coefficients $a_{1}$ and $a_{2}$, as well as $d_{s e}$, are postulated to depend on the parameters that control scouring. 
The practical use of the exponential function requires a priori knowledge of the equilibrium scour depth (Franzetti et al. 1982). Important studies on scouring (e.g., Ettema 1980; Melville and Chiew 1999) have successively assumed that the normalized equilibrium scour depth, $d_{s e} / D_{p}$, does not depend on the sediment coarseness ratio, $D_{p} / D_{50}$, for $D_{p} / D_{50}>\sim 50$. This view has been disputed in the last decade by, e.g., Sheppard et al. $(1995,1999,2004)$ and Lee and Sturm (2009). According to those studies, $d_{s e} / D_{p}$ decreases with increasing sediment coarseness ratio, for $D_{p} / D_{50}>\sim 50$.

In spite of those recent contributions, there is still lack of information on scouring for comparatively high sediment coarseness ratios. The explanation is as follows: for clear water scour, close to the condition of initiation of motion, bed sediment must be such that $D_{50}>\sim 0.6 \mathrm{~mm}$ to avoid ripples; consequently, large sediment coarseness ratios require large values of the pier diameter, $D_{p}$, and of the approach flow depth, $d$, in order to satisfy the simultaneous need to simulate realistic values of flow shallowness, $d / D_{p}$. Also, in order to avoid wall and contraction effects-for large pier diameter and flow depth-wide facilities and flow discharges, that do not exist in most laboratories, are needed.

In this study, the availability of two comparatively large flumes rendered possible to generate additional scour data for values of sediment coarseness ratio in the range $58 \leq D_{p} / D_{50} \leq 465$, while covering flow shallowness values, $d / D_{p}$, in the range $0.5 \leq d / D_{p} \leq 5.0$, for flow intensity, $U / U_{c}$ ( $U=$ average approach flow velocity; $U_{c}=$ critical average velocity for the beginning of sediment motion), close to the condition of initiation of motion $\left(U / U_{c} \approx 1\right)$. A total of 38 tests lasting between 7 and 14 days were run for this purpose.

The data of this study were obtained with the specific objectives of (1) revisiting the influence of sediment coarseness on the equilibrium scour depth and (2) improving scour depth time evolution modeling by making use of the exponential function suggested by Franzetti et al. (1982).

\section{Framework for Analysis}

Pier scour depth at a given instant, $t$, can be described by the following set of independent variables:

$d_{s}=\varphi\left[\begin{array}{l}\text { flow }\left(d, S_{e}, g\right), \text { fluid }(\rho, \nu), \operatorname{bed} \operatorname{material}\left(D_{50}, \sigma_{D}, \rho_{s}\right), \\ \operatorname{pier}\left(D_{p}, K_{\theta}, K_{s}\right), \operatorname{channel}\left(B, S_{0}, K_{g}\right), \operatorname{time}(t)\end{array}\right]$

where apart from the variables already defined, $d_{s}=$ scour depth at instant $t ; S_{e}=$ slope of the energy line; $g=$ acceleration of gravity; $\rho$ and $\nu=$ fluid density and kinematic viscosity, respectively; $\sigma_{D}=$ gradation coefficient of the bed material; $\rho_{s}=$ sediment density; $K_{\theta}$ and $K_{s}=$ coefficients expressing pier alignment and shape, respectively; $B=$ channel width; $S_{0}=$ channel bed slope; and $K_{g}=$ coefficient describing the geometry of the channel cross section.

For uniform flows in wide rectangular channels, $S_{e}=S_{0}$, $K_{g}=1$, and $B$ does not influence scour. In this context, wide channels are those where the effects of flow contraction due to the presence of piers as well as wall effects are negligible. For clear-water flat bed flows, $S_{e}$ can be replaced by both the friction velocity, $u_{*}=\left(\operatorname{gd} S_{e}\right)^{0.5}$, or the average approach flow velocity, $U$. If the bed material is composed of uniform, non-ripple-forming sand, which implies $D_{50}>\sim 0.6 \mathrm{~mm}, \sigma_{D}<1.5$ and $\rho_{s} \approx$ constant, then $\sigma_{D}$ and $\rho_{s}$ can be eliminated from Eq. (1). For cylindrical piers, $K_{s}=1$ and $K_{\theta}=1$. In the case of fully developed flow on a flat bed, where the relation $u_{*} / u_{* c}=U / U_{c}\left(u_{* c}=\right.$ critical bed shear velocity for sediment entrainment) holds, and keeping in mind
Shields' diagram as well as assuming that within the scour hole the flow is fully rough irrespective of the approach flow regime, it can be assumed that the kinematic viscosity, $\nu$, no longer influences the scouring process.

Under these assumptions, Eq. (1) can be transformed into (Fael 2007)

$$
\frac{d_{s}}{D_{p}}=\varphi\left(\frac{d}{D_{p}}, \frac{U}{U_{c}}, \frac{D_{p}}{D_{50}}, \frac{U t}{D_{p}}\right)
$$

For $U / U_{c}=$ constant (usually $U / U_{c} \approx 1.0$ in laboratory conditions so as to maximize the scour depth), nondimensional equilibrium scour depth reads

$$
\frac{d_{s e}}{D_{p}}=\varphi_{1}\left(\frac{d}{D_{p}}, \frac{D_{p}}{D_{50}}\right)
$$

since $t$ no longer interferes.

The first objective of this study aims, in practice, at the improved characterization of Eq. (3). The second objective consists of further specifying the model suggested by Franzetti et al. (1982), in the sequence of the findings of Simarro et al. (2011). The model reads

$$
\frac{d_{s}}{d_{s e}}=1-\exp \left[-a_{1}\left(\frac{U t}{D_{p}}\right)^{a_{2}}\right]
$$

According to the original reference, $a_{2}$ should be constant ( $\left.a_{2} \approx 1 / 3\right)$, while $a_{1}$ is rather small and varies in the range $0.021<a_{1}<0.042$. By comparing Eqs. (2) and (4), it becomes obvious that the model suggested by Franzetti et al. (1982) may be completed by relating $a_{1}$ and $a_{2}$ with the parameters that do not explicitly appear in Eq. (4), i.e., the flow shallowness, $d / D_{p}$, and the sediment coarseness ratio, $D_{p} / D_{50}$. For $U / U_{c}=$ constant, it seems reasonable to assume, a priori, that

$$
\begin{aligned}
& a_{1}=\varphi_{2}\left(\frac{d}{D_{p}}, \frac{D_{p}}{D_{50}}\right) \\
& a_{2}=\varphi_{3}\left(\frac{d}{D_{p}}, \frac{D_{p}}{D_{50}}\right)
\end{aligned}
$$

The experiments reported herein were designed so as to contribute to the definition of the functional relations $\varphi_{1}, \varphi_{2}$, and $\varphi_{3}$ of Eqs. (3), (5), and (6), respectively.

\section{Experimental Setup and Procedure}

Two flumes were used in the experimental study. One, located at the University of Beira Interior, is $28.00 \mathrm{~m}$ long, $2.00 \mathrm{~m}$ wide, and $1.00 \mathrm{~m}$ deep. Discharge was measured by an electromagnetic flow meter with an accuracy of $\pm 0.5 \%$ of full scale. At the entrance of the flume, two honeycomb diffusers aligned with the flow direction smoothed the flow trajectories and guaranteed a uniform transversal flow distribution. Immediately downstream from the diffusers, a 5.00-m-long bed reach was covered with small gravel to provide proper roughness and guarantee fully developed flow. The central reach of the flume, starting at $14.00 \mathrm{~m}$ from the entrance, includes a 3.00-m-long, 2.00-m-wide, and 0.60-m-deep recess box in the channel bed. At the downstream end of the flume, a tailgate allows the regulation of the water depth.

Single vertical cylindrical piers were simulated by PVC pipes with diameters $D_{p}=[50,75,110,160,200,250,315,350,400 \mathrm{~mm}]$, placed at $\sim 1.0 \mathrm{~m}$ from the upstream boundary of the bed recess box. 
The second flume, located at the University of Porto, is $33.15 \mathrm{~m}$ long, $1.00 \mathrm{~m}$ wide, and $1.0 \mathrm{~m}$ deep; its central reach starts at $16.00 \mathrm{~m}$ from the entrance. Provisions similar to the ones described above for the 2.0-m-wide flume (honeycomb and floor roughness) were installed to guarantee similar working conditions for the flow recirculation circuit on this flume. The recess box is $3.20 \mathrm{~m}$ long, $1.0 \mathrm{~m}$ wide and $0.35 \mathrm{~m}$ deep. The maximum pier diameter was $200 \mathrm{~mm}$, so as to minimize contraction effects.

A uniform quartz sand $\left(\rho_{s}=2,650 \mathrm{~kg} \mathrm{~m}^{-3} ; D_{50}=0.86 \mathrm{~mm}\right.$; $\sigma_{D}=1.36$ ) was used to fill each of the recess boxes of the two channels. Prior to each experiment, the sand bed was perfectly leveled. The area located around the pier was covered with a thin metallic plate to avoid uncontrolled scour at the beginning of each experiment. The flumes were filled gradually, imposing a high water depth and low flow velocity. The discharge corresponding to the chosen approach flow velocity was then adjusted to pass through the flumes. The flow depth was regulated by adjusting the downstream tailgates. Once the discharge and flow depth were established, the metallic plates were removed and the experiments started.

Scour immediately initiated and the depth of scour hole was measured, to an accuracy of $\pm 1 \mathrm{~mm}$, with adapted point gauges, approximately every 5 minutes during the first hour. Afterwards, the interval between measurements increased and, after the first day, only a few measurements were carried out each day. When the scour rate was less than approximately $2 \mathrm{~mm}\left(\approx 2 D_{50}\right)$ in 24 hours and at least 7 days had passed, the experiments were stopped. The sand bed approach reach located upstream of the piers stayed undisturbed through the entire duration of the experiments; this long-term stability ensured that the scour depth was not supplemented by upstream bed degradation.

\section{Results and Discussion}

\section{Data Characterization}

The values of the most important control variables and non-dimensional parameters characterizing the experiments are summarized in Table 1. It can be concluded that a reasonably high relative flow depth $\left(0.050 \mathrm{~m} \leq d \leq 0.400 \mathrm{~m} ; 58<d / D_{50}<465\right)$ was always guaranteed. The average flow intensity, $U / U_{c}$, varied in the range $0.93 \leq U / U_{c} \leq 1.04$, with $U_{c}$ being calculated using the predictor of Neil (1967). The aspect ratio $B / d$ was guaranteed to be greater than 5.0, this way avoiding significant wall effects on the flow field.

The ratio of channel width to pier diameter, $B / D_{p}$, was at least 5.0 , being higher than 8.0 in 30 (out of 38) tests and higher than 10.0 in 27 tests. Contraction scour seemed absent since no

Table 1. Characteristic Control Variables and Nondimensional Parameters of Experiments

\begin{tabular}{|c|c|c|c|c|c|c|c|c|c|c|c|c|}
\hline Test & $\begin{array}{c}B \\
(\mathrm{~m})\end{array}$ & $\begin{array}{c}d \\
(\mathrm{~mm})\end{array}$ & $\begin{array}{c}D_{p} \\
(\mathrm{~mm})\end{array}$ & $\begin{array}{c}U \\
(\mathrm{~m} / \mathrm{s})\end{array}$ & $\begin{array}{c}t_{d} \\
\text { (hour) }\end{array}$ & $\begin{array}{c}d_{s m} \\
(\mathrm{~mm})\end{array}$ & $\begin{array}{c}d_{s e} \\
(\mathrm{~mm})\end{array}$ & $B / D_{p}$ & $U / U_{c}$ & $d / D_{p}$ & $D_{p} / D_{50}$ & $d_{s e} / D_{p}$ \\
\hline 1 & 2.0 & 55 & 110 & 0.28 & 170 & 153.6 & 180.1 & 18.2 & 0.97 & 0.5 & 127.9 & 1.64 \\
\hline 2 & 2.0 & 80 & 160 & 0.29 & 168 & 195.0 & 226.2 & 12.5 & 0.97 & 0.5 & 186.0 & 1.41 \\
\hline 3 & 2.0 & 100 & 200 & 0.29 & 170 & 225.0 & 263.1 & 10.0 & 0.97 & 0.5 & 232.6 & 1.32 \\
\hline 4 & 2.0 & 125 & 250 & 0.30 & 168 & 249.5 & 282.1 & 8.0 & 0.97 & 0.5 & 290.7 & 1.13 \\
\hline 5 & 2.0 & 158 & 315 & 0.29 & 223 & 315.3 & 348.1 & 6.3 & 0.93 & 0.5 & 366.3 & 1.10 \\
\hline 6 & 2.0 & 175 & 350 & 0.33 & 306 & 335.4 & 337.3 & 5.7 & 1.04 & 0.5 & 407.0 & 0.96 \\
\hline 7 & 2.0 & 200 & 400 & 0.31 & 288 & 376.6 & 409.2 & 5.0 & 0.96 & 0.5 & 465.1 & 1.02 \\
\hline 8 & 2.0 & 50 & 50 & 0.27 & 168 & 104.2 & 115.6 & 40.0 & 0.97 & 1.0 & 58.1 & 2.31 \\
\hline 9 & 2.0 & 75 & 75 & 0.28 & 168 & 142.5 & 163.9 & 26.7 & 0.97 & 1.0 & 87.2 & 2.18 \\
\hline 10 & 2.0 & 110 & 110 & 0.29 & 168 & 179.9 & 198.9 & 18.2 & 0.97 & 1.0 & 127.9 & 1.81 \\
\hline 11 & 1.0 & 160 & 160 & 0.30 & 285 & 222.6 & 231.1 & 6.3 & 0.95 & 1.0 & 186.0 & 1.44 \\
\hline 12 & 1.0 & 200 & 200 & 0.31 & 261 & 283.4 & 296.5 & 5.0 & 0.96 & 1.0 & 232.6 & 1.48 \\
\hline 13 & 2.0 & 250 & 250 & 0.32 & 263 & 324.0 & 365.0 & 8.0 & 0.98 & 1.0 & 290.7 & 1.46 \\
\hline 14 & 2.0 & 315 & 315 & 0.33 & 186 & 351.9 & 388.3 & 6.3 & 0.98 & 1.0 & 366.3 & 1.23 \\
\hline 15 & 2.0 & 350 & 350 & 0.33 & 291 & 372.6 & 408.7 & 5.7 & 0.97 & 1.0 & 407.0 & 1.17 \\
\hline 16 & 2.0 & 400 & 400 & 0.33 & 224 & 405.6 & 448.4 & 5.0 & 0.95 & 1.0 & 465.1 & 1.12 \\
\hline 17 & 2.0 & 75 & 50 & 0.28 & 168 & 105.4 & 118.9 & 40.0 & 0.97 & 1.5 & 58.1 & 2.38 \\
\hline 18 & 2.0 & 113 & 75 & 0.30 & 168 & 159.1 & 175.8 & 26.7 & 0.97 & 1.5 & 87.2 & 2.34 \\
\hline 19 & 1.0 & 165 & 110 & 0.30 & 241 & 180.1 & 224.6 & 9.1 & 0.96 & 1.5 & 127.9 & 2.04 \\
\hline 20 & 2.0 & 225 & 160 & 0.33 & 267 & 272.2 & 305.7 & 12.5 & 1.01 & 1.4 & 186.0 & 1.91 \\
\hline 21 & 2.0 & 300 & 200 & 0.33 & 262 & 308.7 & 360.6 & 10.0 & 0.98 & 1.5 & 232.6 & 1.80 \\
\hline 22 & 2.0 & 375 & 250 & 0.33 & 221 & 338.8 & 373.8 & 8.0 & 0.96 & 1.5 & 290.7 & 1.50 \\
\hline 23 & 2.0 & 100 & 50 & 0.29 & 170 & 114.6 & 127.1 & 40.0 & 0.97 & 2.0 & 58.1 & 2.54 \\
\hline 24 & 2.0 & 150 & 75 & 0.30 & 169 & 154.0 & 162.7 & 26.7 & 0.97 & 2.0 & 87.2 & 2.17 \\
\hline 25 & 2.0 & 220 & 110 & 0.33 & 216 & 197.5 & 208.9 & 18.2 & 1.01 & 2.0 & 127.9 & 1.90 \\
\hline 26 & 2.0 & 300 & 160 & 0.33 & 330 & 247.2 & 267.1 & 12.5 & 0.98 & 1.9 & 186.0 & 1.67 \\
\hline 27 & 2.0 & 400 & 200 & 0.33 & 219 & 298.8 & 329.4 & 10.0 & 0.95 & 2.0 & 232.6 & 1.65 \\
\hline 28 & 2.0 & 125 & 50 & 0.30 & 168 & 111.8 & 111.0 & 40.0 & 0.97 & 2.5 & 58.1 & 2.22 \\
\hline 29 & 1.0 & 188 & 75 & 0.31 & 191 & 138.3 & 146.7 & 13.3 & 0.96 & 2.5 & 87.2 & 1.96 \\
\hline 30 & 2.0 & 275 & 110 & 0.33 & 184 & 215.8 & 234.3 & 18.2 & 0.98 & 2.5 & 127.9 & 2.13 \\
\hline 31 & 2.0 & 375 & 160 & 0.33 & 313 & 241.1 & 278.8 & 12.5 & 0.96 & 2.3 & 186.0 & 1.74 \\
\hline 32 & 1.0 & 150 & 50 & 0.30 & 173 & 94.5 & 109.7 & 20.0 & 0.96 & 3.0 & 58.1 & 2.19 \\
\hline 33 & 2.0 & 225 & 75 & 0.33 & 197 & 156.3 & 170.6 & 26.7 & 1.01 & 3.0 & 87.2 & 2.27 \\
\hline 34 & 2.0 & 330 & 110 & 0.33 & 169 & 193.1 & 222.6 & 18.2 & 0.96 & 3.0 & 127.9 & 2.02 \\
\hline 35 & 2.0 & 200 & 50 & 0.31 & 170 & 115.9 & 133.7 & 40.0 & 0.96 & 4.0 & 58.1 & 2.67 \\
\hline 36 & 2.0 & 300 & 75 & 0.33 & 314 & 173.7 & 197.6 & 26.7 & 0.98 & 4.0 & 87.2 & 2.63 \\
\hline 37 & 2.0 & 250 & 50 & 0.33 & 237 & 100.3 & 116.6 & 40.0 & 1.00 & 5.0 & 58.1 & 2.33 \\
\hline 38 & 2.0 & 375 & 75 & 0.33 & 315 & 161.5 & 184.3 & 26.7 & 0.96 & 5.0 & 87.2 & 2.46 \\
\hline
\end{tabular}


bed degradation was observed over the contracted cross sections. With one exception (test 19 ), values of $B / D_{p}<10$ corresponded to flow shallowness $d / D_{p}=[0.50 ; 1.00]$. According to Ballio et al. (2009), for such a range of values of $d / D_{p}$, significant increases of scour depth ascribable to contraction effects may be observed only for $B / D_{p}<3$. Ballio et al. (2009) also pointed out that contraction manifests itself mostly at early stages of the scour process. Breusers and Raudkivi (1991) suggested that contraction scour is negligible for values of $B / D_{p}$ as low as 2.0 to 2.5. Cardoso and Bettess (1999) have shown that, shortly after the beginning of the scouring process, the flow field remains practically unaffected over the flat bed out of the scour hole since the intercepted discharge tends to be conveyed through the scour holes. Thus, it seems safe to conclude that, if eventually present, contraction effects were minor in the present study.

The pier Reynolds number, $\mathrm{R}_{p}=U D_{p} / \nu$, varied between 13,625 (test 8) and 13,2000 (test 16). According to the literature, it may be assumed that viscous effects are negligible. In fact, the conditions suggested by Oliveto and Hager (2002)- $D_{50}>$ $0.8 \mathrm{~mm}$-or quoted by Franzetti et al. (1994)- $\mathrm{R}_{p}=U D_{p} / \nu>$ 7,000 - are both satisfied. However, the effect of viscosity on scouring seems to be a topic for further research since none of the reported conditions guarantees that the approach flow is rough turbulent.

On average (see http://w3.ualg.pt/ rlanca/largepierstime.pdf), the duration of the experiments was 2.51 times longer than the time to equilibrium given by the criterion suggested by Melville and Chiew (1999): $\Delta d_{s}<0.05 D_{p}, \Delta d_{s}=$ increment of scour depth in 24 hours. Also, that duration was 2.52 times longer than the time to equilibrium implicitly adopted by Ettema (1980): $\Delta d_{s}<1 \mathrm{~mm}$ in 4 hours.

The approach flow depth values were adjusted in accordance with the different pier diameters tested in order to achieve the range of flow shallowness values, $d / D_{p} \approx[0.5,1.0,1.5,2.0,2.5,3.0,4.0$, 5.0]. Sediment coarseness, $D_{p} / D_{50}$, took nine values in the range $58.1 \leq D_{p} / D_{50} \leq 465.1$, covering comparatively high values of this parameter, enabling an enhanced characterization of the sediment coarseness effect on the scour depth.

After screening, NCHRP (2011) identified 233 and 210 valid tests published to date, respectively, on clear-water and live-bed scour at single piers. Those numbers reduce to 109 tests falling in the range $0.90 \leq U / U_{c} \leq 1.10$. The vast majority of these tests were rather short: only 12 lasted $t_{d} \geq 4$ days ( $t_{d}=$ test duration). For the range of sediment coarseness covered by the present experimental campaign, i.e, for $D_{p} / D_{50}>\sim 60$, only 9 tests correspond to $t_{d} \geq 4$ days and an even smaller number, 6, correspond to $t_{d} \geq 7$ days. These numbers only marginally increase to 13 , for $t_{d} \geq 4$ days, and to 9 , for $t_{d} \geq 7$ days, if $0.85 \leq U / U_{c} \leq 1.20$. It is clear that a distinctive contribution of the present study is the long duration data of careful clear-water scour experiments for comparatively wide piers.

Time records of the scour depths are available at http://w3.ualg .pt/ rlanca/largepierstime.pdf. The tests 1 to 7 , corresponding to $d / D_{p}=0.5$, are plotted in Fig. 1(a) in the coordinates suggested by Oliveto and Hager (2002, 2005), i.e.,

$$
\frac{Z \sigma_{D}^{0.5}}{F_{d}^{1.5}} \quad \text { and } \quad T=\frac{t}{t_{R}}
$$

where

$$
\begin{aligned}
Z & =\frac{d_{s}}{z_{R}} \quad z_{R}=\left(D_{p}^{2} d\right)^{1 / 3} \\
F_{d} & =\frac{U}{\left(\Delta g D_{50}\right)^{1 / 2}} \quad t_{R}=\frac{z_{R}}{\sigma_{D}^{1 / 3}\left(\Delta g D_{50}\right)^{1 / 2}}
\end{aligned}
$$

Here, the gradation coefficient is defined as $\sigma_{D}=\left(D_{84} / D_{16}\right)^{0.5}$ and $\Delta=\left(\rho_{s}-\rho\right) / \rho$. Fig. 1(a) also plots the predictor of Oliveto and Hager (2005), as a solid line, by assuming a shape factor of 1 (cylindrical pier), as well as the $\pm 25 \%$ band around the predictor. Similar plots were produced for the other seven $d / D_{p}$ groups; they do not substantially differ from Fig. 1(a). The inspection of this figure reveals that the predictor proposed by Oliveto and Hager (2005) does not match the data. The plots do not either display any horizontal plateau, a denoting factor of the equilibrium phase as proposed by Cardoso and Bettess (1999) for vertical wall abutments. The applicability of the time-factor model of Melville and Sheppard as quoted at NCHRP (2011) was also not supported by the data [see Fig. 1(b)], particularly in the early stages of the scour process. The reasons for these discrepancies probably derive from the difficulty to fully characterize the functional relation of Eq. (1).

According to Franzetti et al. (1994), half of the experiments should have reached equilibrium since $U t_{d} / D_{p}$ exceeded $2 \times 10^{6}$. However, equilibrium scour does not seem to have been unambiguously reached in any of the present experiments. Yet, it is postulated here that finite equilibrium scour depth must exist. It is recognized that the probability of occurrence of a sufficiently
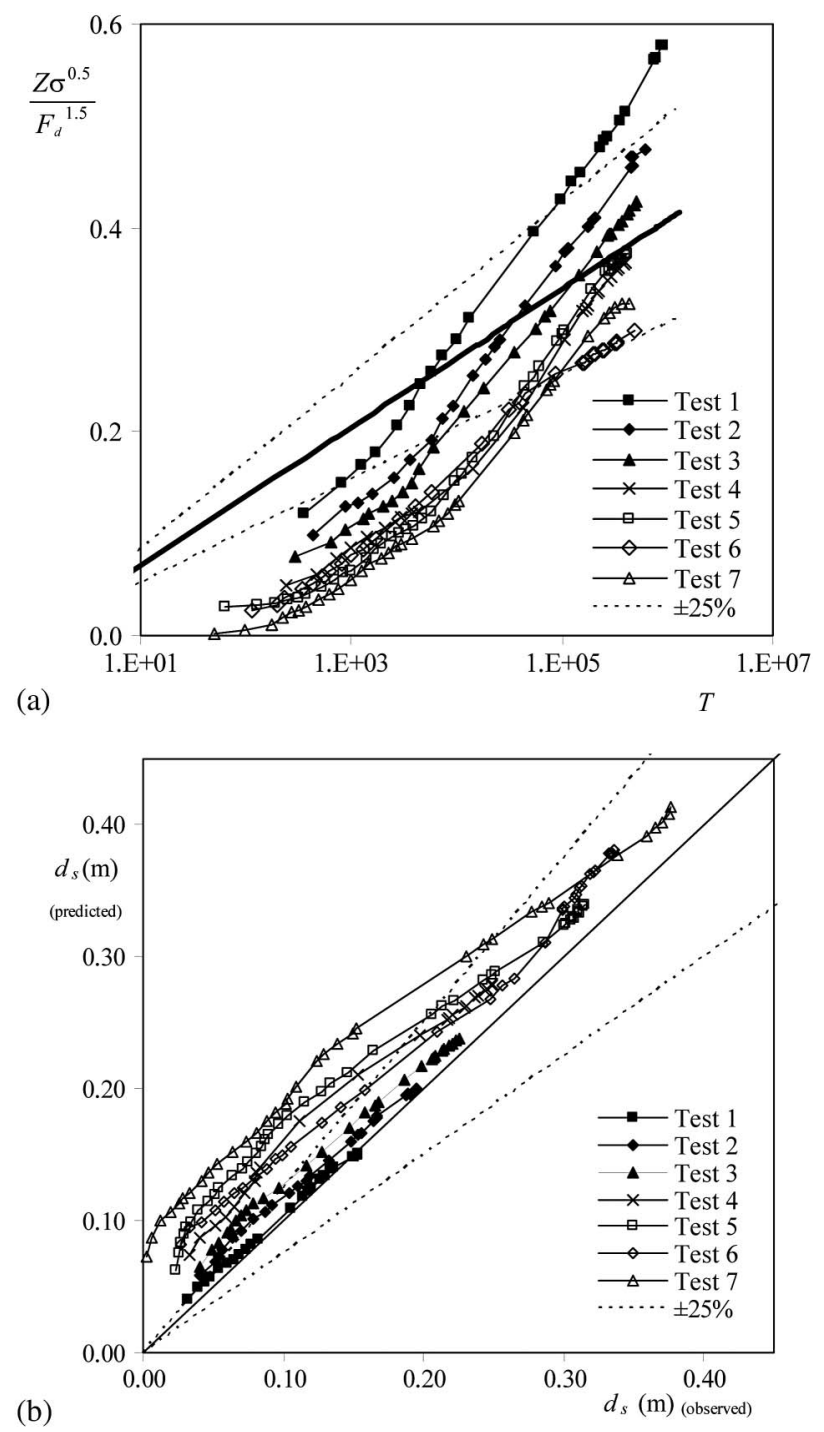

Fig. 1. Time evolution of scour depth measurements versus the predictors of (a) Oliveto and Hager (2005) and (b) Melville and Sheppard as quoted at NCHRP (2011), for $d / D_{p}=0.5$ 


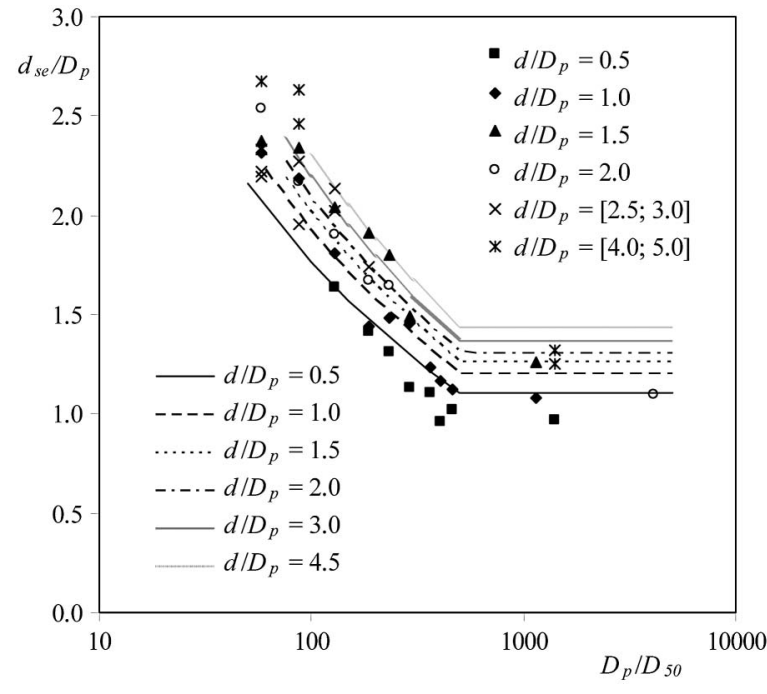

Fig. 2. Functional dependence of $d_{\mathrm{se}} / D_{p}$ on $D_{p} / D_{50}$

strong turbulent event capable of entraining sediment grains from the scour hole will never be null though this probability decreases as scour develops, tending asymptotically to zero. Thus, it is also assumed that the time needed to achieve finite equilibrium scour may be rather large, conceptually infinite. For this reason, scour depth records were fitted by using regression with the following polynomial function:

$$
\begin{aligned}
d_{s}= & p_{1}\left(1-\frac{1}{1+p_{1} p_{2} t}\right)+p_{3}\left(1-\frac{1}{1+p_{3} p_{4} t}\right) \\
& +p_{5}\left(1-\frac{1}{1+p_{5} p_{6} t}\right)
\end{aligned}
$$

so as to obtain the equilibrium scour depth, $d_{\text {se }}$, as suggested by Lança et al. (2010). In the above polynomial equation, parameters $p_{1}, p_{2}, \ldots, p_{6}$ have no physical meaning; however, it is obvious that, for $t=\infty, d_{s}=d_{s e}=p_{1}+p_{3}+p_{5}$. The equilibrium scour depths obtained through the fitting procedure are included in Table 1, together with the scour depth, $d_{s m}$, measured at end of the experiment.

The equilibrium scour depths, $d_{s e}$, obtained through extrapolation are, on average, $10 \%$ higher than $d_{s m}$. Defining $d_{s e E}=$ scour depth at time to equilibrium implicitly adopted by Ettema (1980) and $d_{\text {sem }}=$ scour depth at time to equilibrium defined according to Melville and Chiew (1999), it can be concluded that $d_{s e E} / d_{s m} \approx$ $d_{s e M} / d_{s m}=0.91 \pm 0.04 ; \quad d_{s e E} / d_{s e}=0.82 \pm 0.06 ; \quad d_{s e M} / d_{s e}=$ $0.82 \pm 0.05$ (see again http://w3.ualg.pt/ rlanca/largepierstime .pdf). From the 233 clear-water experiments retained by NCHRP (2011), 184 include information on $t_{d}$; among these, $\approx 80 \%$ were performed at the School of Auckland and are likely to have adopted the equilibrium criteria of Ettema (1980) or Melville and Chiew (1999). It seems that such experiments, though the closest to equilibrium to date, produced scour depths between $\approx 80 \%$ and $\approx 90 \%$ of the true equilibrium scour depth.

\section{Equilibrium Scour Depth}

The values of $d_{s e} / D_{p}$ are plotted against $D_{p} / D_{50}$ in Fig. 2. Data of six long duration clear-water experiments $\left(t_{d} \geq 6\right.$ days) by Sheppard et al. (2004) for $D_{p} / D_{50}>500$ and $U / U_{c}$ sufficiently close to $1.0(0.85$ to 1.21$)$ are also included in the figure for completeness. It should be mentioned here that these original data were used instead of those retained by NCHRP (2011) since both sets do not exactly coincide, particularly, in terms of the duration of tests. These literature data are characterized in Table 2 as identified by the prefix $S h$. Fig. 2 separates the data-those of this study as well as those of Sheppard et al. (2004)_into six classes of $d / D_{p}$. Due to experimental limitations of the present study the figure includes few values for $d / D_{p}>3.0$. It is clear that the parameter $D_{p} / D_{50}$ influences $d_{s e} / D_{p}$, leading to decreasing normalized scour depth as $D_{p} / D_{50}$ increases in the range of the study. This conclusion qualitatively corroborates the findings of Sheppard et al. $(1995,1999,2004)$ and Lee and Sturm (2009). According to Sheppard (2004), pressure gradients in the proximity of small size piers are larger than near larger ones, inducing larger forces on the sediment grains around the former. For a given sediment size, some local scour mechanisms diminish in magnitude with increasing pier width. Ettema et al. (2006) investigated the scale of the turbulence in the wake region for different pier sizes and related the differences with the decreasing dependence of scour on increasing pier width. Lee and Sturm (2009) related the decrease of the relative scour depth with different large scale unsteadiness of the horseshoe vortex for different pier sizes and sediment coarseness. These explanations remain unproven and deserve to be checked against detailed measurements of flow field around different-scale piers.

In spite of the scatter, Fig. 3, which includes the envelop curves of the equilibrium scour data, shows that $d_{s e} / D_{p}$ increases

\begin{tabular}{|c|c|c|c|c|c|c|c|c|c|c|c|c|c|}
\hline Test & $\begin{array}{c}B \\
(\mathrm{~m})\end{array}$ & $\begin{array}{c}D \\
(\mathrm{~m})\end{array}$ & $\begin{array}{l}D_{p} \\
(\mathrm{~m})\end{array}$ & $\begin{array}{c}D_{50} \\
(\mathrm{~mm})\end{array}$ & $\begin{array}{c}U \\
(m / s)\end{array}$ & $\begin{array}{c}t_{d} \\
\text { (day) }\end{array}$ & $\begin{array}{l}d_{s m} \\
(\mathrm{~m})\end{array}$ & $\begin{array}{l}d_{s e} \\
(\mathrm{~m})\end{array}$ & $U / U_{c}$ & $B / D_{p}$ & $d / D_{p}$ & $D_{p} / D_{50}$ & $d_{s e} / D_{p}$ \\
\hline Sh2 & 6.10 & 1.19 & 0.31 & 0.22 & 0.31 & 6.8 & 0.26 & 0.41 & 0.97 & 19.7 & 3.90 & 1386 & 1.32 \\
\hline Sh3 & 6.10 & 1.27 & 0.91 & 0.80 & 0.47 & 15.0 & 1.11 & 1.15 & 0.85 & 6.7 & 1.39 & 1143 & 1.26 \\
\hline Sh4 & 6.10 & 0.87 & 0.91 & 0.80 & 0.39 & 6.0 & 0.69 & 0.99 & 0.87 & 6.7 & 0.95 & 1143 & 1.09 \\
\hline Sh12 & 6.10 & 1.22 & 0.31 & 0.22 & 0.40 & 10.7 & 0.38 & 0.39 & 1.21 & 19.7 & 4.00 & 1386 & 1.26 \\
\hline Sh13 & 6.10 & 0.18 & 0.31 & 0.22 & 0.30 & 9.0 & 0.30 & 0.30 & 1.11 & 19.7 & 0.59 & 1386 & 0.97 \\
\hline Sh14 & 6.10 & 1.81 & 0.91 & 0.22 & 0.30 & 24.2 & 0.79 & 1.00 & 0.94 & 6.7 & 1.98 & 4155 & 1.10 \\
\hline \multirow[t]{6}{*}{$\mathrm{Et}^{\mathrm{a}}$} & - & 0.60 & 0.15 & 0.80 & 0.43 & 13.1 & 0.315 & 0.315 & 0.96 & - & 4.00 & 187 & 2.10 \\
\hline & - & 0.60 & 0.15 & 0.84 & 0.44 & 12.4 & 0.339 & 0.339 & 1.00 & - & 4.00 & 179 & 2.26 \\
\hline & - & 0.60 & 0.15 & 0.84 & 0.44 & 13.1 & 0.314 & 0.314 & 0.95 & - & 4.00 & 179 & 2.09 \\
\hline & - & 0.60 & 0.10 & 0.80 & 0.43 & 8.1 & 0.226 & 0.226 & 0.96 & - & 5.91 & 127 & 2.23 \\
\hline & - & 0.60 & 0.10 & 0.84 & 0.44 & 4.9 & 0.225 & 0.225 & 1.00 & - & 5.91 & 121 & 2.21 \\
\hline & - & 0.60 & 0.10 & 0.84 & 0.44 & 10.0 & 0.226 & 0.226 & 0.95 & - & 5.91 & 121 & 2.23 \\
\hline $\mathrm{Gf}^{\mathrm{a}}$ & - & 0.23 & 0.15 & 2.10 & 0.66 & 4.4 & 0.259 & 0.259 & 0.93 & - & 1.55 & 71 & 1.73 \\
\hline
\end{tabular}

Table 2. Characteristic Control Variables and Nondimensional Parameters of Long-Duration Tests Selected from Literature

Note: Sh = Sheppard et al. (2004); Et = Ettema (1980); Gf = Graf (1995).

${ }^{\mathrm{a}}$ As reported in NCHRP (2011). 


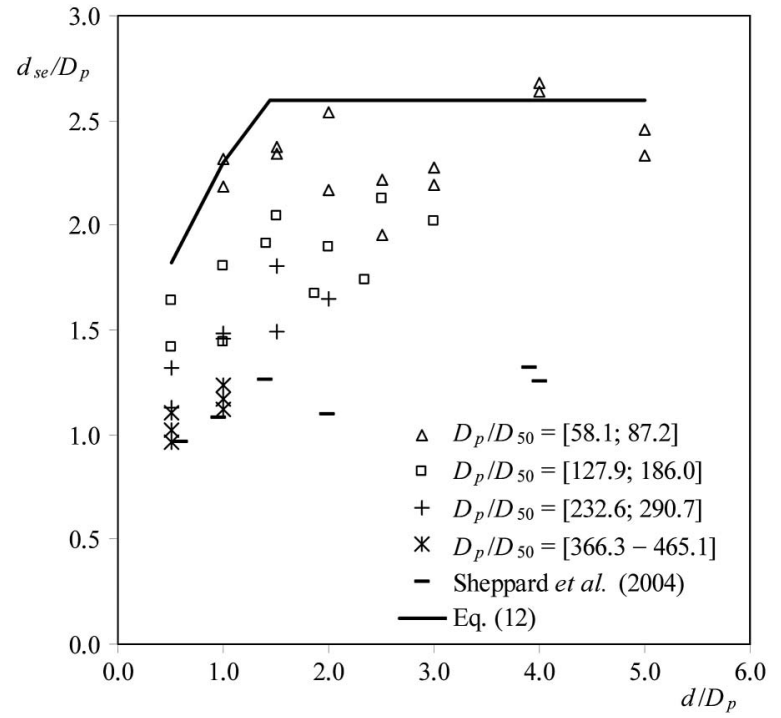

Fig. 3. Envelope curve for the functional dependence of $d_{s e} / D_{p}$ on $d / D_{p}$

with $d / D_{p}$ for a given class of $D_{p} / D_{50}$, within the range $0.5 \leq$ $d / D_{p} \leq 5.0$.

The double dependence of $d_{s e} / D_{p}$ on flow shallowness, $d / D_{p}$, and sediment coarseness, $D_{p} / D_{50}$, is captured by the following regression equations:

$$
\frac{d_{s e}}{D_{p}}= \begin{cases}7.3\left(\frac{D_{p}}{D_{50}}\right)^{-0.29}\left(\frac{d}{D_{p}}\right)^{0.12} & \text { for } 60 \leq \frac{D_{p}}{D_{50}} \leq 500 \\ 1.2\left(\frac{d}{D_{p}}\right)^{0.12} & \text { for } \frac{D_{p}}{D_{50}}>500\end{cases}
$$

In the range $D_{p} / D_{50} \leq 500$, the determination coefficient is $r^{2}=0.90$ and the root mean square error is $\mathrm{RMSE}=0.12$, for $0.5 \leq d / D_{p} \leq 2.0$, while $\mathrm{RMSE}=0.22$, for $2.0<d / D_{p} \leq 5.0$. According to Eq. (10), the effect of $D_{p} / D_{50}$ is constant for $D_{p} / D_{50}>\approx 500$. This result corroborates the finding of Lee and Sturm (2009) who stated that, for $D_{p} / D_{50}>400, d_{\mathrm{se}} / D_{p} \approx$ 1.3. It is also clear that the classical upper bound defined by $d_{s e} / D_{p} \approx 2.4$ for narrow piers was exceeded for sediment coarseness $D_{p} / D_{50}=[58.1-87.2]$. This result is in line with the findings of Sheppard et al. (2004) and Lee and Sturm (2009), these last referring to field data where $d_{s e} / D_{p}$ largely exceeds 2.4 . Since these data correspond to different values of $U / U_{c}$, piers' shape and piers' alignment, they were back corrected to the standard cylindrical pier and may inherently convey uncertainties. Likewise, the values of $d_{s e} / D_{p}$ obtained in the present study cannot be excluded to reflect the assessment of the equilibrium scour depth as occurring at $t=\infty$. Thus, for prudence, the curves included in Fig. 3 do not completely envelop all the data and, for practical applications, the following upper-bound scour predictor is suggested:

$$
\frac{d_{s e}}{D_{p}}=K_{d} K_{D 50}
$$

where $K_{d}$ is the predictor of Melville (1997) modified to read

$$
K_{d}= \begin{cases}2.3\left(\frac{d}{D_{p}}\right)^{1 / 3} & 0.50 \leq \frac{d}{D_{p}} \leq 1.45 \\ 2.6 & \frac{d}{D_{p}}>1.45\end{cases}
$$

and $K_{D 50}$ is given by

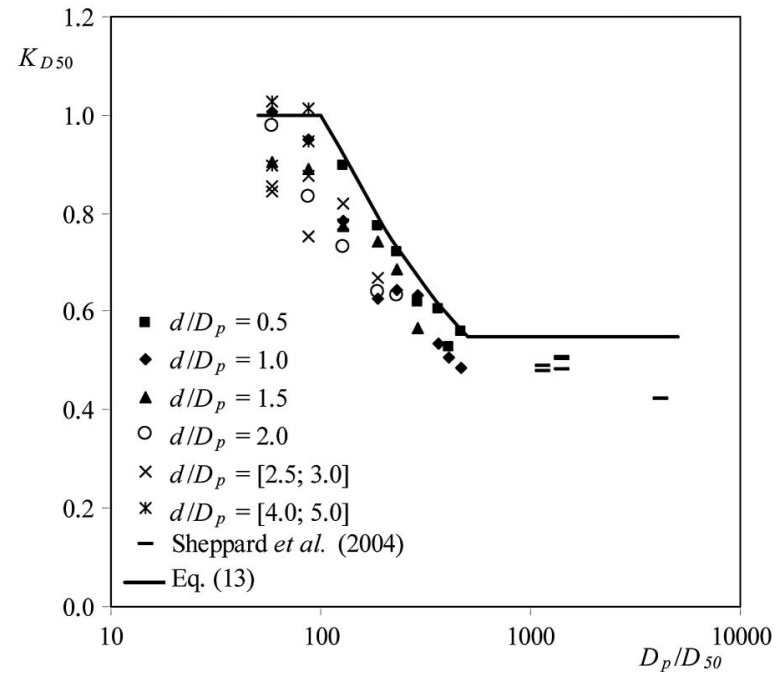

Fig. 4. Functional dependence of $K_{D 50}$ on $D_{p} / D_{50}$

$$
K_{D 50}= \begin{cases}1.0 & 60<\frac{D_{p}}{D_{50}} \leq 100 \\ 5.8\left(\frac{D_{p}}{D_{50}}\right)^{-0.38} & 100<\frac{D_{p}}{D_{50}} \leq 500 \\ 0.55 & 500<\frac{D_{p}}{D_{50}}\end{cases}
$$

Eq. (13) constitutes the envelope curve of the $K_{D 50}$ data plotted in Fig. 4. The values of $K_{D 50}$ were back calculated from the values of $d_{s e} / D_{p}$ reported in Table 1 by assuming $K_{d}$ to be given by the modified predictor of Melville (1997), Eq. (12).

In practice the use of Eqs. (11)-(13) for safe upper bound scour depth prediction requires the use of appropriate multiplying factors to take into account the effects of flow intensity, pier shape, pier alignment, gradation coefficient of bed the material, flow contraction, cross-section shape, and time. The upper bound value of $d_{s e} / D_{p}$, occurring for values of $D_{p} / D_{50}<100$, is not critical for sand bed $\left(D_{50}<2 \mathrm{~mm}\right)$ since the predicted equilibrium scour depths will be similar irrespective of the tuning of the upper bound predictor. The importance of the present contribution arises for $D_{p} / D_{50}>100$ by reinforcing the proposals by Sheppard et al. (2004) and Lee and Sturm (2009).

\section{Time Evolution of Scour Depth}

Since the value of $d_{s e}$ is known for each experiment (Table 1), Eq. (4) could be fitted to each scour depth time record and the output of the fitting process were the values of $a_{1}$ and $a_{2}$. The associated determination coefficients, $r^{2}$, were always higher than 0.97. The values of $a_{1}$ and $a_{2}$ are included in Table 3 and plotted against $D_{p} / D_{50}$ in Fig. 5 .

From Table 3, it can be concluded that $a_{1}$ varies in the range $0.005 \leq a_{1} \leq 0.080$, with an average value of 0.031 , while $a_{2}$ varies within the range $0.212 \leq a_{2} \leq 0.458$, with an average value of 0.311. These intervals of $a_{1}$ and $a_{2}$ contain the proposals of Franzetti et al. (1982), i.e., $a_{1}=0.028$ and $a_{2}=1 / 3$. From Fig. 5, it is clear that $a_{1}$ displays a clear dependence on the sediment coarseness, $D_{p} / D_{50}$. The dependence of $a_{2}$ on the same parameter is also clear. No obvious variation of $a_{1}$ or $a_{2}$ with $d / D_{p}$ was identified. The coefficients $a_{1}$ and $a_{2}$ relate with $D_{p} / D_{50}$ as follows:

$$
\begin{aligned}
a_{1} & =1.22\left(\frac{D_{p}}{D_{50}}\right)^{-0.764} \\
a_{2} & =0.09\left(\frac{D_{p}}{D_{50}}\right)^{0.244}
\end{aligned}
$$


Table 3. Values of $a_{1}$ and $a_{2}$

\begin{tabular}{lccccc}
\hline Test & $a_{1}$ & $a_{2}$ & Test & $a_{1}$ & $a_{2}$ \\
\hline 1 & 0.037 & 0.275 & 20 & 0.018 & 0.328 \\
2 & 0.024 & 0.319 & 21 & 0.025 & 0.301 \\
3 & 0.020 & 0.334 & 22 & 0.011 & 0.388 \\
4 & 0.012 & 0.381 & 23 & 0.064 & 0.233 \\
5 & 0.006 & 0.438 & 24 & 0.034 & 0.297 \\
6 & 0.013 & 0.410 & 25 & 0.029 & 0.310 \\
7 & 0.005 & 0.458 & 26 & 0.020 & 0.329 \\
8 & 0.070 & 0.232 & 27 & 0.015 & 0.352 \\
9 & 0.046 & 0.249 & 28 & 0.041 & 0.314 \\
10 & 0.034 & 0.292 & 29 & 0.042 & 0.281 \\
11 & 0.019 & 0.360 & 30 & 0.037 & 0.277 \\
12 & 0.017 & 0.356 & 31 & 0.017 & 0.321 \\
13 & 0.019 & 0.340 & 32 & 0.070 & 0.224 \\
14 & 0.017 & 0.366 & 33 & 0.041 & 0.268 \\
15 & 0.018 & 0.358 & 34 & 0.031 & 0.282 \\
16 & 0.015 & 0.374 & 35 & 0.057 & 0.229 \\
17 & 0.080 & 0.212 & 36 & 0.027 & 0.275 \\
18 & 0.053 & 0.249 & 37 & 0.025 & 0.277 \\
19 & 0.036 & 0.257 & 38 & 0.032 & 0.266 \\
\hline
\end{tabular}

(a)
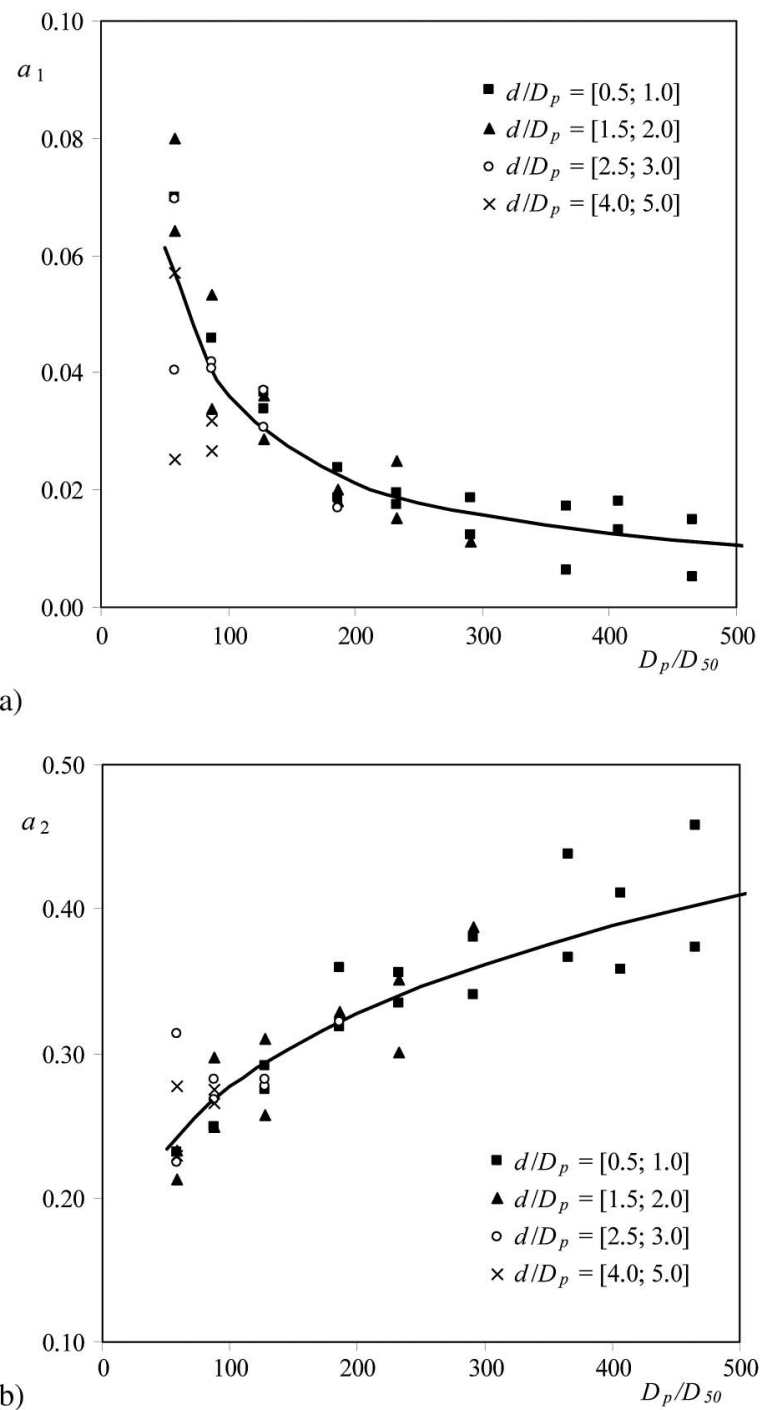

Fig. 5. Functional dependence of (a) $a_{1}$ on $D_{p} / D_{50}$; (b) $a_{2}$ on $D_{p} / D_{50}$
The determination coefficients are $r^{2}=0.76$ and 0.77 , respectively. From the above, the use of the model of Franzetti et al. (1982) for the prediction of scour depth time evolution, Eq. (4), is suggested. The new contribution of this study is the specification of coefficients $a_{1}$ and $a_{2}$ through Eqs. (14) and (15). It is worth stressing that this contribution only applies to cylindrical piers inserted in uniform, fully developed turbulent flows, in wide rectangular channels with a flat bed composed of uniform, nonripple-forming sand, close to the condition of beginning of sediment motion $\left(U / U_{c} \approx 1.0\right)$.

\section{Validation of the New Predictors}

Excluding the data of Sheppard et al. (2004)—which was used to derive Eqs. (10)-(13)—only data of Ettema (1980) and Graf (1995) are found in NCHRP (2011) for tests' duration $t_{d} \geq 4$ days and $0.9 \leq U / U_{c} \leq 1.1$. It is assumed here that such data correspond to tests that sufficiently approached the equilibrium. It must be retained here that, in the present experimental study, $d_{s 4} / d_{\text {se }}=$ $0.82 \pm 0.06\left(d_{s 4}=\right.$ scour depth measure at $t=4$ days $)$. Those data
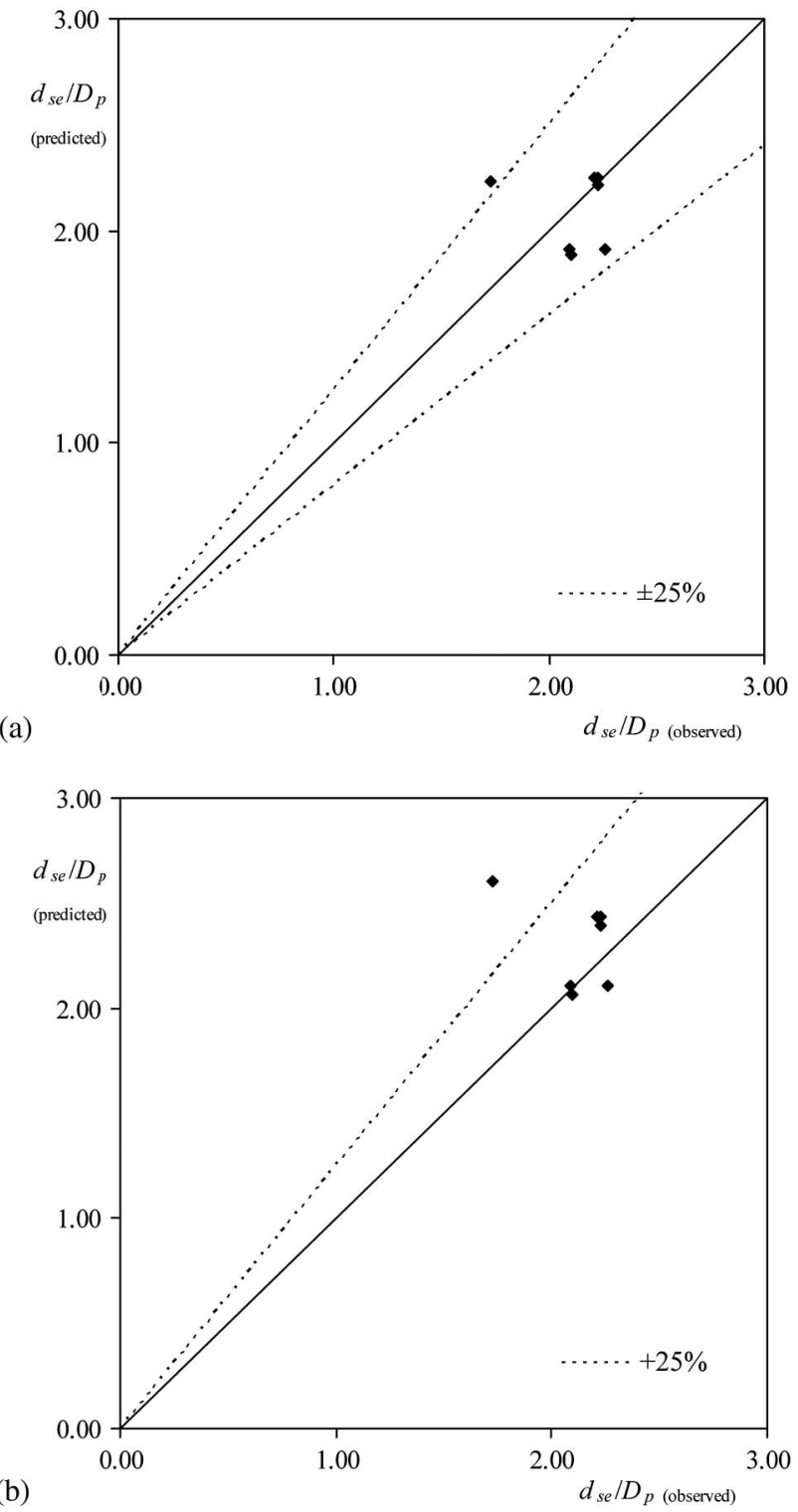

Fig. 6. Predicted versus observed scour depth: (a) central predictions by Eq. (10); (b) upper-bound predictions by Eqs. (11)-(13) 
Table 4. Characteristic Variables and Nondimensional Parameters of Tests Used to Validate the Suggested Scour Time Evolution Model

\begin{tabular}{|c|c|c|c|c|c|c|c|c|c|c|c|c|c|c|}
\hline Test & $\begin{array}{c}B \\
(\mathrm{~m}) \\
\end{array}$ & $\begin{array}{c}d \\
(\mathrm{~mm})\end{array}$ & $\begin{array}{c}D_{p} \\
(\mathrm{~mm})\end{array}$ & $\begin{array}{c}D_{50} \\
(\mathrm{~mm})\end{array}$ & $\sigma_{D}$ & $\begin{array}{c}U \\
(\mathrm{~m} / \mathrm{s})\end{array}$ & $\begin{array}{c}t_{d} \\
\text { (day) } \\
\end{array}$ & $\begin{array}{l}d_{s m} \\
(\mathrm{~m})\end{array}$ & $\begin{array}{l}d_{s e} \\
(\mathrm{~m})\end{array}$ & $U / U_{c}$ & $B / D_{p}$ & $d / D_{p}$ & $D_{p} / D_{50}$ & $d_{s e} / D_{p}$ \\
\hline R1 & 2.00 & 50 & 110 & 0.86 & 1.36 & 0.27 & 7.0 & 0.154 & 0.157 & 0.97 & 18.2 & 0.45 & 127.9 & 1.43 \\
\hline R2 & 2.00 & 80 & 75 & 0.86 & 1.36 & 0.29 & 7.0 & 0.144 & 0.160 & 0.97 & 26.7 & 1.07 & 87.2 & 2.13 \\
\hline R3 & 2.00 & 110 & 75 & 0.86 & 1.36 & 0.29 & 7.0 & 0.142 & 0.155 & 0.97 & 26.7 & 1.47 & 87.2 & 2.07 \\
\hline R4 & 2.00 & 113 & 250 & 0.86 & 1.36 & 0.30 & 7.0 & 0.249 & 0.282 & 0.97 & 8.0 & 0.45 & 290.7 & 1.13 \\
\hline R5 & 2.00 & 75 & 160 & 0.86 & 1.36 & 0.28 & 7.0 & 0.201 & 0.240 & 0.97 & 12.5 & 0.47 & 186.0 & 1.50 \\
\hline R6 & 2.00 & 200 & 100 & 0.86 & 1.36 & 0.31 & 7.0 & 0.199 & 0.218 & 0.96 & 20.0 & 2.00 & 116.3 & 2.18 \\
\hline R7 & 2.00 & 200 & 150 & 0.86 & 1.36 & 0.31 & 7.0 & 0.228 & 0.252 & 0.96 & 13.3 & 1.33 & 174.4 & 1.68 \\
\hline Si1 & 0.82 & 160 & 75 & 0.86 & 1.36 & 0.27 & 34.9 & 0.168 & 0.173 & 0.88 & 10.9 & 2.13 & 87.2 & 2.31 \\
\hline $\mathrm{Si} 2$ & 0.82 & 160 & 80 & 0.86 & 1.36 & 0.30 & 45.6 & 0.196 & 0.210 & 0.94 & 10.3 & 2.00 & 93.0 & 2.63 \\
\hline $\mathrm{Si} 3$ & 0.82 & 160 & 80 & 1.28 & 1.46 & 0.34 & 29.7 & 0.130 & 0.130 & 0.93 & 10.3 & 2.00 & 62.5 & 1.62 \\
\hline $\mathrm{Si} 4$ & 0.82 & 150 & 75 & 1.28 & 1.46 & 0.34 & 24.9 & 0.139 & 0.140 & 0.93 & 10.9 & 2.00 & 58.6 & 1.87 \\
\hline $\mathrm{Si} 5$ & 0.82 & 130 & 63 & 1.28 & 1.46 & 0.34 & 29.0 & 0.129 & 0.128 & 0.93 & 13.0 & 2.06 & 49.2 & 2.04 \\
\hline Gr1 & 0.80 & 150 & 75 & 1.28 & 1.46 & 0.40 & 4.0 & 0.121 & 0.126 & 1.00 & 10.7 & 2.00 & 58.6 & 1.68 \\
\hline Gr2 & 2.00 & 250 & 90 & 0.86 & 1.36 & 0.34 & 6.2 & 0.179 & 0.193 & 1.00 & 22.2 & 2.78 & 104.7 & 2.14 \\
\hline Gr3 & 2.00 & 250 & 120 & 0.86 & 1.36 & 0.34 & 6.1 & 0.225 & 0.244 & 1.00 & 16.7 & 2.08 & 139.5 & 2.03 \\
\hline
\end{tabular}

Note: $\mathrm{R}=$ Reference test; $\mathrm{Si}=$ Simarro et al. (2011); $\mathrm{Gr}=$ Grimaldi (2005).
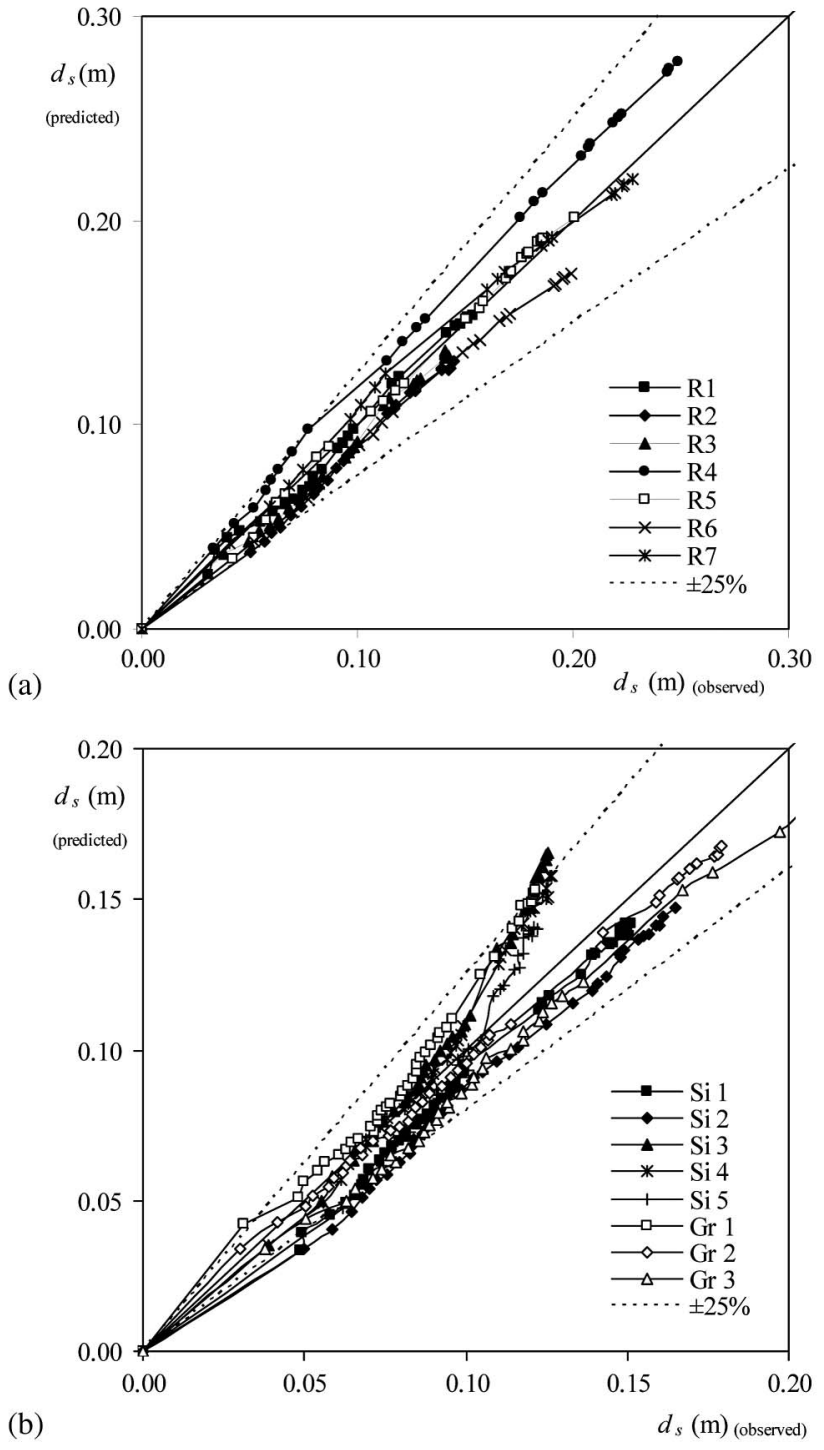

Fig. 7. Predicted versus observed scour depth time evolution: (a) data of the present study; (b) data of Simarro et al. (2011) and Grimaldi (2005) are characterized in Table 2; they were used for validation of the suggested equilibrium scour depth predictors. Fig. 6(a) shows that, with one exception, Eq. (10) predicts the observed equilibrium scour depths within deviations of $\pm 25 \%$ around the line of perfect agreement, while Fig. 6(b) indicates that Eqs. (11)-(13) constitute a reasonable upper-bound predictor of equilibrium scour depth. The exceptions on Fig. 6 correspond to the experiment of Graf (1995), where $t_{d}=4$ days, which highlights the crucial importance of the time effect on the equilibrium scour depth.

Simarro et al. (2011) have published five long-duration experiments on scouring at cylindrical piers that respect the restrictions of the present study. The data from these experiments, as well as from seven additional tests carried out in this study, were used for validation of the suggested scour time evolution model. Three experiments from Grimaldi (2005) were also included in the analysis. The control variables of these data sources are summarized in Table 4. Their scour depth time records are also included in http:// w3.ualg.pt/ rlanca/largepierstime.pdf. Other time evolution data sources identified in the literature (see, e.g., NCHRP 2011) were not assessed since they are published in graphical form only and the experimental conditions are not known.

Eq. (4) was used to predict the scour depth time evolution. The outputs are compared with measurements in Fig. 7, where the results obtained in this study are included in Fig. 7(a) while the experiments of Simarro et al. (2011) and Grimaldi (2005) are used in Fig. 7(b).

The inspection of Fig. 7 reveals that the suggested predictor describes the scour depth time evolution for independent data sets within deviations of $\pm 25 \%$ around the line of perfect agreement.

\section{Conclusions}

The most important conclusions of this study are as follows:

1. The equilibrium scour depth decreases with $D_{p} / D_{50}$, for $D_{p} / D_{50}>\sim 100$, corroborating the findings of Sheppard et al. $(1995,1999,2004)$ and Lee and Sturm (2009), which implies refuting the classical assumption according to which the equilibrium scour depth would not depend on $D_{p} / D_{50}$ for $D_{p} / D_{50}>\sim 25$. The sediment size factor, $K_{D 50}$, may be obtained through Eq. (13). 
2. Safe upper-bound predictions of the equilibrium scour depth may be obtained through Eq. (11), valid for cylindrical piers inserted in uniform, fully-developed turbulent flows in wide rectangular channels with flat bed composed of uniform, non-ripple-forming sand, flow intensity $U / U_{c} \approx 1.0$, $D_{p} / D_{50}>\approx 60$ and $d / D_{p} \geq 0.5$.

3. The exponential model of Franzetti et al. (1982), Eq. (4), properly describes the time evolution of scour depth as soon as its coefficients $a_{1}$ and $a_{2}$ are specified through Eqs. (14) and (15), respectively. This contribution applies for $U / U_{c} \approx 1.0,60<$ $D_{p} / D_{50}<500$ and $0.5 \leq d / D_{p} \leq 5.0$.

\section{Acknowledgments}

The authors wish to acknowledge the financial support of the Portuguese Foundation for Science and Technology through the research project PTDC/ECM/101353/2008.

\section{Notation}

The following symbols are used in this paper:

$a_{1}, a_{2}=$ model coefficients;

$B=$ channel width;

$D_{p}=$ pier diameter;

$D_{50}=$ median grain size;

$d=$ approach flow depth;

$d_{s}=$ scour depth at instant $t$

$d_{s e}=$ equilibrium scour depth;

$d_{s e E}=$ equilibrium scour depth according to Ettema (1980);

$d_{s e M}=$ equilibrium scour depth according to Melville and Chiew (1999);

$g=$ acceleration of gravity;

$K_{D 50}=$ sediment coarseness factor;

$K_{d}=$ flow shallowness factor;

$K_{g}=$ coefficient describing the geometry of the channel cross-section;

$K_{s}=$ pier shape coefficient;

$K_{\theta}=$ coefficient describing the alignment of the pier;

$S_{e}=$ slope of the energy line;

$S_{0}=$ channel bottom slope;

$T=$ non-dimensional time;

$t=$ time;

$t_{d}=$ test duration;

$t_{\mathrm{eE}}=$ time to equilibrium according to Ettema (1980);

$t_{e M}=$ time to equilibrium according to Melville and Chiew (1999);

$U=$ average approach flow velocity;

$U_{c}=$ critical average velocity for the beginning of sediment motion;

$u_{*}=$ approach flow friction velocity;

$u_{* c}=$ critical bed shear velocity for sediment entrainment;

$\nu=$ kinematic viscosity;

$\rho=$ fluid density;

$\rho_{s}=$ sediment density; and

$\sigma_{D}=$ gradation coefficient of the bed material.

\section{References}

Ballio, F., Teruzzi, A., and Radice, A. (2009). "Constriction effects in clearwater scour at abutments." J. Hydraul Eng., 135(2), 140-145.
Breusers, H. N. C., and Raudkivi, A. (1991). Scouring, hydraulic structures design manual, A. A. Balkema, Rotterdam, The Netherlands.

Cardoso, A. H., and Bettess, R. (1999). "Effects of time and channel geometry on scour at bridge abutments." J. Hydraul. Eng., 125(4), 388-399.

Ettema, R. (1980). "Scour at bridge piers." Rep. No. 216, Univ. of Auckland, Auckland, New Zealand.

Ettema, R., Kirkil, G., and Mostafa, E. A. (2006). "Similitude of large-scale turbulence in experiments on local scour at cylinders." J. Hydraul. Eng., 132(1), 33-40.

Fael, C. M. S. (2007). "Erosões localizadas junto de encontros de pontes e respectivas medidas de protecção.” Ph.D. thesis, Univ. of Beira Interior, Covilhã, Portugal (in Portugese).

Franzetti, S., Larcan, E., and Mignosa, P. (1982). "Influence of tests duration on the evaluation of ultimate scour around circular piers." Proc., Int. Conf. on the Hydraulic Modeling of Civil Engineering Structures, BHRA Fluid Engineering, Coventry, England, 381-396.

Franzetti, S., Malavasi, S., and Piccinin, C. (1994). "Sull'erosione alla base delle pile di ponte in acque chiare." Proc., XXIV Convegno di Idraulica e Costruzioni Idrauliche, Vol. 2, GNDCI-CNR, Italy, 13-24 (in Italian).

Graf, W. H. (1995). "Load scour around piers." Annual Rep., Laboratoire de Recherches Hydrauliques, École Polytechnique Fédérale de Lausanne, Lausanne, Switzerland.

Grimaldi, C. (2005). "Non-conventional countermeasures against local scouring at bridge piers." Ph.D. thesis, Universita' della Calabria, Cosenza, Italy.

Kothyari, U. C., Hager, W. H., and Oliveto, G. (2007). "Generalized approach for clear-water scour at bridge foundation elements." J. Hydraul. Eng., 133(11), 1229-1240.

Lança, R., Fael, C., and Cardoso, A. (2010). "Assessing equilibrium clearwater scour around single cylindrical piers." River Flow 2010, A. Dittrich, et al., eds., Bundesanstalt für Wasserbau, Germany, 1207-1213.

Lee, S. O., and Sturm, T. W. (2009). "Effect of sediment size scaling on physical modeling of bridge scour." J. Hydraul. Eng., 135(10), 793-802.

Melville, B. W. (1997). "Pier and abutment scour: integrated approach." J. Hydraul. Eng., 123(2), 125-136.

Melville, B. W., and Chiew, Y. M. (1999). "Time scale for local scour at bridge piers." Journal of Hydraulic Engineering, 125(1), 59-65.

National Cooperative Highway Research Program (NCHRP). (2011). "Scour at wide piers and long skewed piers." Rep. 682, Transportation Research Board, Washington, DC.

Neil, C. R. (1967). "Mean velocity criterion for scour of coarse uniform bed-material." Proc., 12th IAHR Congress, IAHR, Forth Collins, CO, Vol. 3(C6), 46-54.

Oliveto, G., and Hager, W. H. (2002). "Temporal evolution of clear-water pier and abutment scour." J. Hydraul. Eng., 128(9), 811-820.

Oliveto, G., and Hager, W. H. (2005). "Further results to time-dependent local scour at bridge elements." J. Hydraul. Eng., 131(2), 97-105.

Sheppard, D. M. (2004). "Overlooked local scour mechanism.” Transportation Research Record 1890, Transportation Research Board, Washington, DC, 107-111.

Sheppard, D. M., Odeh, M., and Glasser, T. (2004). "Large scale Clearwater local pier scour experiments." J. Hydraul. Eng., 130(10), 957-963.

Sheppard, D. M., Ontowirjo, B., and Zhao, G. (1995). "Local scour near single piles in steady currents." Proc., 1st Hydraulics Engineering Conf., ASCE, Reston, VA, 371-376.

Sheppard, D. M., Ontowirjo, B., and Zhao, G. (1999). "Local scour near single piles in steady currents." Stream Stability and Scour at Highway Bridges, Compendium of papers, ASCE Water Resources Conferences1991-1998, E. V. Richardson and P. F. Lagasse, eds., ASCE, Reston, VA, 1809-1813.

Simarro, G., Fael, C., and Cardoso, A. (2011). "Estimating equilibrium scour depth at cylindrical piers in experimental studies." J. Hydraul. Eng., 137(9), 1089-1093. 